\title{
National Ignition Facility Sub-System Design Requirements Ancillary Systems SSDR 1.5.6
}

J. Spann

R. Reed

P. VanArsdall

E. Bliss

September 5, 1996

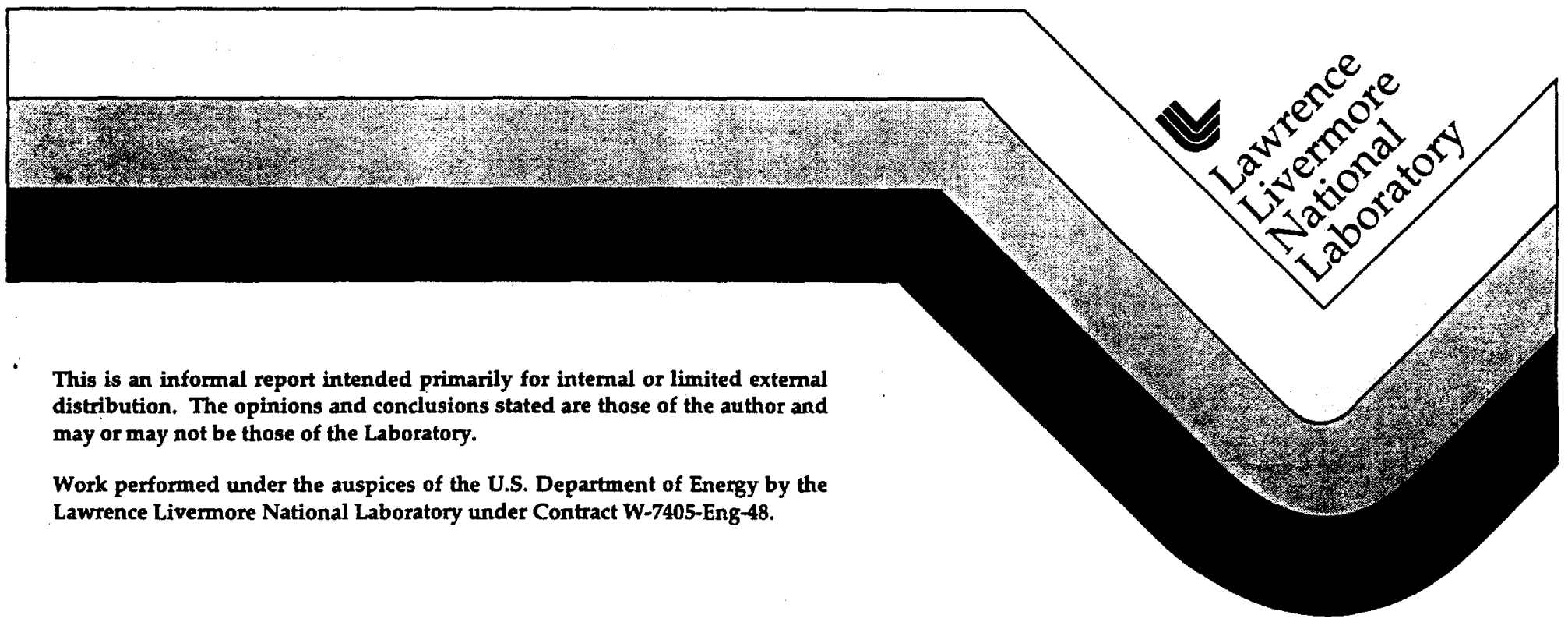




\section{DISCLAMMER}

This document was prepared as an account of work sponsored by an agency of the United States Government. Neither the United States Government nor the University of California nor any of their employees, makes any warranty, express or implied, or assumes any legal liability or responsibility for the accuracy, completeness, or usefulness of any information, apparatus, product, or process disclosed, or represents that its use would not infringe privately owned rights. Reference herein to any specific commercial product, process, or service by trade name, trademark, manufacturer, or otherwise, does not necessarily constitute or imply its endorsement, recommendation, or favoring by the United States Government or the University of California. The views and opinions of authors expressed herein do not necessarily state or reflect those of the United States Government or the University of California, and shall not be used for advertising or product endorsement purposes.

This report has been reproduced directly from the best available copy.

Available to DOE and DOE contractors from the Office of Scientific and Technical Information P.O. Box 62, Oak Ridge, TN 37831

Prices available from (615) 576-8401, FTS 626-8401

Available to the public from the National Technical Information Service

U.S. Department of Commerce 5285 Port Royal Rd., Springfield, VA 22161 


\section{National Ignition Facility}

\section{Sub-System Design Requirements}

\section{Ancillary Systems \\ SSDR 1.5.6}

Revision 2

5 September 1996

Prepared by:

J. Spann, Video Subsystem Engineer

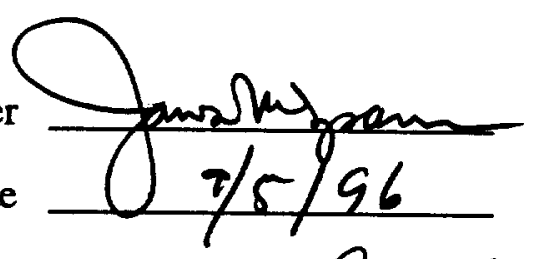

R. Reed, Facility Environmental Monitor

Subsystem Engineer

Date $9 / 5 / 96$

P. VanArsdall, Integrated Computer Controls

Lead Engineer Pauly van ansol

Date

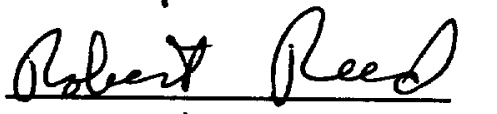

E. Bliss, System Controls System Engineer

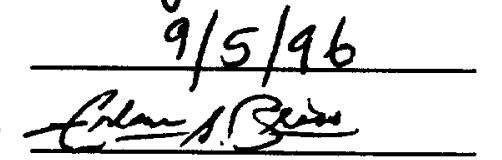

Date

$10 / 5 / 96$

Special Equipment Engineering Approval:

R. Sawicki, NIF Associate Project Engineer

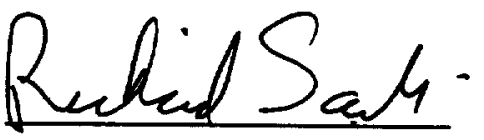

Date

$10 / 21 / 46$

Engineering Review Board Approval:

S. Kumpan, NIF Project Engineer

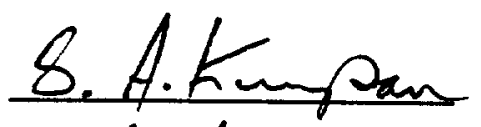
Approval Date

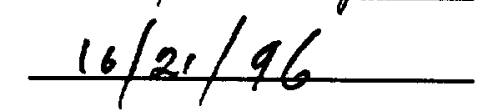




\section{Table of Contents}

\section{Paragraph}

1.0

2.0

2.1

2.2

2.3

2.4

2.5

2.6

3.0

3.1

3.1 .1

3.1.1.1

3.1.1.2

3.1.1.3

3.1 .3

3.1.3.1

3.1.3.2

3.1 .4

3.1 .5

3.2 .00

3.2 .01 .1

3.2.01.2

3.2.01.3

3.2 .01 .4

3.2 .01 .5

3.2 .01 .6

3.2.01.7

3.2 .01 .8

3.2 .08

3.2 .09

3.2 .10

3.2.11

3.2 .12

3.2 .13

3.2 .14

3.2 .15

3.2 .16

3.2 .17

3.2 .18

3.2.18.1

3.2.18.2

3.2.18.3

3.2 .18 .4

3.2 .18 .5

3.2.19

\section{Title}

Scope

Applicable Documents

Applicable NIF Project Documents

Applicable US Government Orders and Standards

Applicable National Consensus Codes and Standards

Applicable LLNL Standards

Supporting Documentation Standards

References

Requirements and Verification

System Definition

System Description

System Description, TV Distribution System

System Description, Communications and Surveillance System

System Description, Facility Environmental System

System Diagrams

TV Distribution System

Facility Monitor Block Diagram

System Interfaces

Major Subsystems

Functional Requirements

Facility Environmental Monitor Measurement \& Logging Interval

Facility Environmental Monitor Measurement, Machine Interlocks

Facility Environmental Monitor, Relative Humidity Monitor

Facility Environmental Monitor, Temperature Monitor

Facility Environmental Monitor, SF Vacuum Monitor, Roughing

Facility Environmental Monitor, SF Vacuum Monitor, Hi-Vac

Facility Environmental Monitor, Pockels Cell Vacuum Monitor

Facility Environmental Monitor, Amplifier Oxygen Monitor

Video Distribution

Video, Variable Classified

Analog TV Video Interface

TV Sensors Synchronization

TV Pulse Laser Operation

TV Surveillance System

Optical Communications Safety

Communications

FEP Software Requirement Specification

QA Level Requirement

Lifetime, Replaceability, Reliability, Availability, Maintainability

Lifetime

Replaceability

Reliability

Availability

Maintainability

Recovery From an Abnormal Event 
3.2 .20

3.2.20.1

3.2.20.2

3.2.20.3

3.2.20.4

3.2 .21

3.2 .22

3.2 .23

3.4

3.4 .1

3.4 .2

6.0
Environmental/EMI Requirements

Environmenta//EMI Requirements, Temperature and Humidity

Environmenta//EMI Requirements, Plenum Approved/CL2 Cabling

EMI Requirements

Ionizing Radiation

Segmented and Concurrent Operation

Human Factors

Documentation and Records

Logistics

Spares

Maintenance

Revision Record 


\subsection{Scope}

This System Design Requirement document establishes the performance, design, development, and test requirements for the Ancillary Systems, WBS 1.5.6 which is part of the NIF Integrated Computer Control System (ICCS). This document responds directly to the requirements detailed in ICCS (WBS 1.5) which is the document directly above.

\subsection{Applicable Documents}

This section lists DOE orders, codes, and standards which are applicable to the NIF Integrated Computer Control System. The applicable portions of these documents apply. Applicable LLNL standards are being considered contingent upon the decision of final site selection.

\subsection{Applicable NIF Project Documents}

National Ignition Facility Functional Requirements and Primary Criteria, Revision 1.4, Mar 96.

\subsection{Applicable US Government Orders and Standards}

US. Government DOE General Orders:

DOE 5700.6C - Quality Assurance (flowdown from FRPC and SDR4)

US. Government DOE Orders relating to Safeguards and Security:

Does not apply to this section.

\subsection{Applicable National Consensus Codes and Standards \\ General Standards: \\ Do not apply to this document.}

Safety Standards:

Do not apply to this document.

Software and Electronic Standards:

Ethernet IEEE-802.3 Local Area Network for Data Communications

FDDI Fiber Distributed Data Interface, ANSI Standard X3.139-1987

RS-232C EIA Serial interface standard

RS-485 EIA Multi-drop serial interface standard

IEEE-488 Standard Digital Interface for Programmable Instrumentation, ANSI/IEEE Std 488.1-1987 and ANSI/IEEE Std 488.2-1987

VMEbus IEEE-1014

RS-170 EIA Video interface standard

Ada 83 ANSIMIL-STD-1815A-1983, programming language

Ada 95 International Standard ANSI/ISO/IEC-8652:1995, January 1995

X11 X Window System, Version 11, windows graphics standard, MIT X Consortium

OSF/Motif Motif graphical user interface, Open Systems Foundation

Postscript Text and graphics printing language, Adobe Systems Inc.

POSIX IEEE-1003 portable application programming environment

TCP/IP Protocol stack for network communications

OSIISO Open Systems Interconnect protocol stack for network communications

OSF/DCE Distributed Computing Environment, Open Systems Foundation

OSF/DME Distributed Management Environment, Open Systems Foundation

\subsection{Applicable LLNL Standards}

LLNL NIF Grounding Plan, L-17346-1 


\subsection{Supporting Documentation Standards}

Instrument Society of America, ISA-S5.1, Instrumentation Symbols and Identification

Instrument Society of America, ISA-S5.2, Binary Logic Diagrams for Process Operations

Instrument Society of America, ISA-S5.3, Graphics Symbols for Distributed Control/Shared Display

Instrumentation, Logic and Computer Systems

Instrument Society of America, ISA-S5.4, Instrument Loop Diagrams

Instrument Society of America, ISA-S5.5, Graphics Symbols for Process Displays

ANSI/IEEE Std 730.1-1989, IEEE Standard for Software Quality Assurance Plans

Software Guidelines Standards, Practices, and Conventions (Final DRAFT), Applications Development

Department, Lawrence Livermore National Laboratory, August 10, 1992

ANSI/IEEE Std 830-1984, IEEE Guide for Software Requirements Specification .

ANSIIEEE Std 1016-1987, IEEE Recommended Practice for Software Design Descriptions

ANSI/IEEE Std 828-1983, IEEE Standard for Software Configuration Management Plans

ANSI/IEEE Std 982.1-1988, IEEE Standard Dictionary for Measures to Produce Reliable Software

ANSI/IEEE Std 982.2-1988, IEEE Guide for the Use of IEEE Standard Dictionary of Measures to Produce

Reliable Software

The Software Productivity Consortium, Ada Quality and Style Guidelines for Professional Programmers

ANSI/IEEE Std 1063-1987, IEEE Standard for Software User Documentation

\subsection{References}

NIF-LLNL-95-044/L-15958-2, National Ignition Facility Quality Assurance Program Plan, September 1995. NIF-LLNL-94-017/L-15958-5, NIF Ancillary Software Quality Assurance Plan, January 12, 1994

NIF-LLNL-93058, National Ignition Facility Functional Requirements and Primary Criteria

\subsection{Requirements and Verification}

\subsection{System Definition}

\subsubsection{System Description}

\subsubsection{System Description, TV Distribution System}

The television distribution system routes approximately 1,000 alignment TV sensors to the automatic alignment system FEPs and to operator console monitors where manual alignment is performed. Additional capacity is reserved for other facility users. A preemptive routing architecture and video data compression reduces the total bandwidth required without imposing significant constraints. Distribution of the digitized video is via LAN.

A small self-contained classified TV system services the sensors required to install and align the classified experimental target and associated target-viewing diagnostics. This equipment is located in and operated from a classified control room. A security-approved disconnection unit provides the means for the TV cameras serviced by this system to be reconnected to the main TV distribution system when the target room is used for unclassified experiments.

\subsubsection{System Description, Communications and Surveillance System}

A communications system provides voice services for use by personnel to help coordinate typical activities associated with construction, operations, and maintenance. The services consist of an intercom system between control rooms and equipment areas and an associated portable radio system for use anywhere in the facility.

The Surveillance System provides a separate set of work area TV cameras, switching system and control room monitors for observing variable high hazard areas and viewing galleries. 


\subsubsection{System Description, Facility Environmental System}

The facility environmental monitoring system measures and records temperature, humidity, pressure, and oxygen content at various points in the laser and throughout the facility using commercial data acquisition units. These measurements are required because the performance of many laser components is sensitive to these environmental parameters.

\subsubsection{System Diagrams}

\subsubsection{TV Distribution System}

Operator Consoles

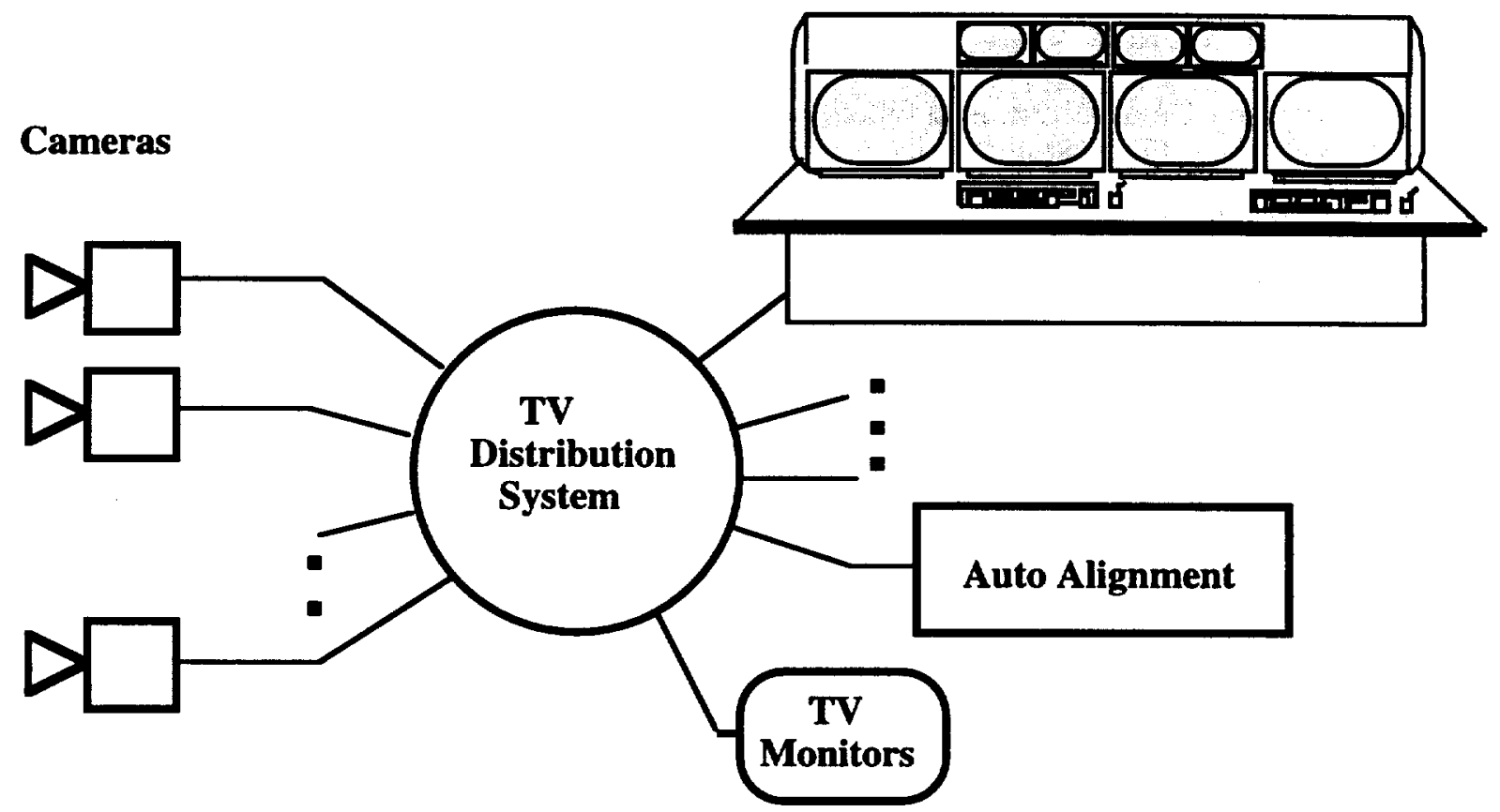




\subsubsection{Facility Monitor Block Diagram}

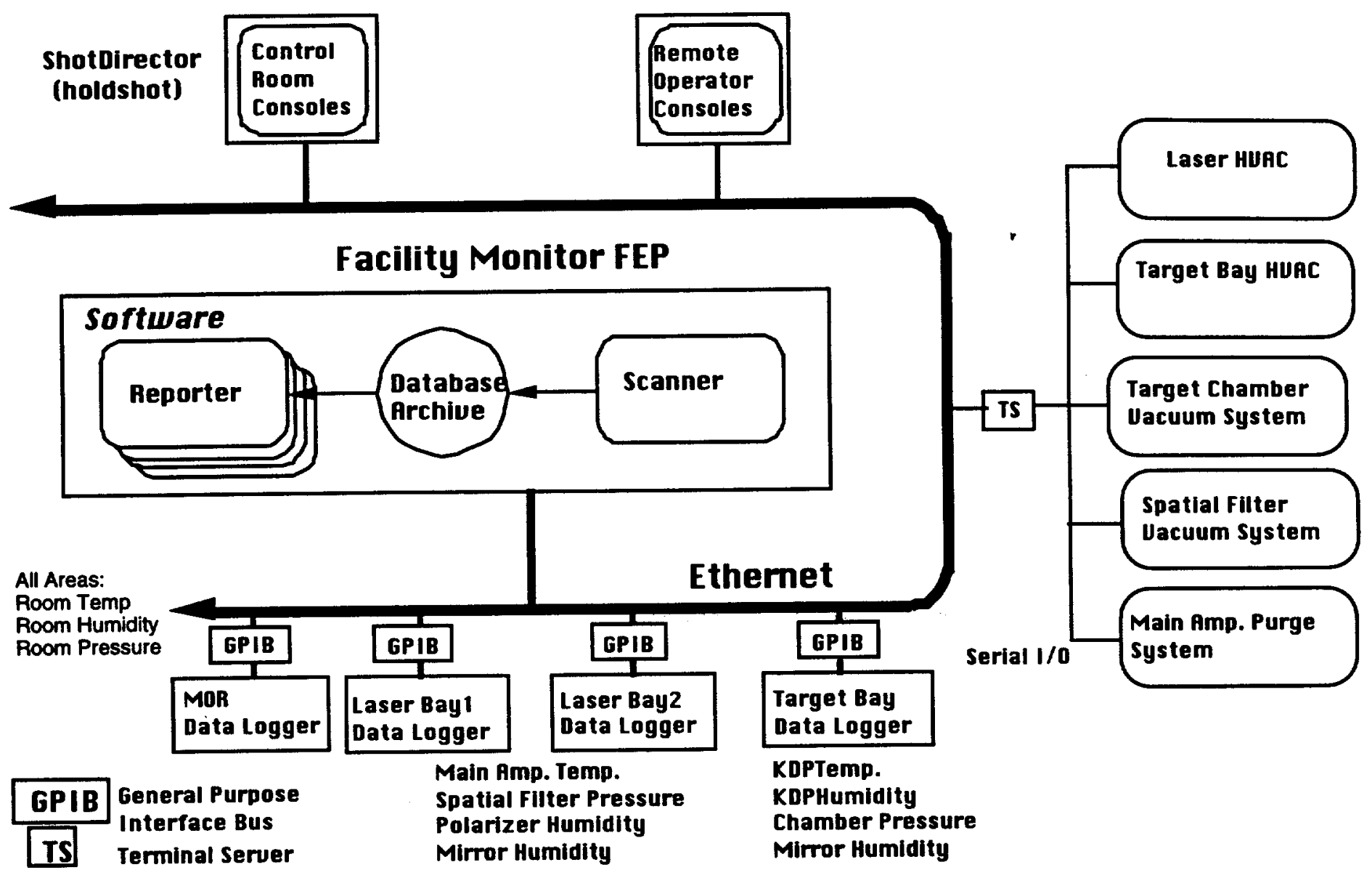




\subsubsection{System Interfaces}

The TV Distribution System has interfaces to the following WBS systems:

$\begin{array}{ll}\text { WBS 1.5.1.2 } & \text { Computer System (network) } \\ \text { WBS 1.5.1.4 } & \text { Control Room Consoles } \\ \text { WBS 1.5.1.5 } & \text { Remote Consoles } \\ \text { WBS 1.5.2 } & \text { Supervisory Software } \\ \text { WBS 1.5.3 } & \text { Integrated Timing System } \\ \text { WBS 1.5.5 } & \text { Automatic Alignment } \\ \text { WBS 1.5.6.1 } & \text { Video Distribution } \\ \text { WBS 1.8.3 } & \text { Target Diagnostics } \\ \text { WBS 1.7.1.3 } & \text { Target Alignment } \\ \text { WBS 1.7.3 } & \text { Wavefront Control } \\ \text { WBS 1.7.2 } & \text { Beam Diagnostics } \\ \text { WBS 1.7.1 } & \text { Alignment Systems } \\ \text { WBS 1.3.1 } & \text { OPG Modulator } \\ \text { WBS 1.3.1.1 } & \text { OPG in MOR } \\ \text { WBS 1.3.1.4 } & \text { OPG/Optical Fiducial } \\ \text { WBS 1.3.1.5 } & \text { OPG/Preamp }\end{array}$

The Communication System has interfaces to the following WBS systems:

\begin{tabular}{|c|c|}
\hline WB & Control Room C \\
\hline WE & Remote Consoles \\
\hline 1.2 .2 & Facility (radio paging) \\
\hline$S 1.2 .2 .1$ & Laser Building(paging) \\
\hline WBS 1.2 .2 .2 & Target Building(paging) \\
\hline & OAB (pa \\
\hline
\end{tabular}

The Facility Environmental Monitor System has interfaces to the following WBS systems:

$\begin{array}{ll}\text { WBS } 1.5 .1 .2 & \text { Computer System (network) } \\ \text { WBS 1.4.2 } & \text { Cavity Spatial Filter Vacuum System (vacuum) } \\ \text { WBS 1.4.2 } & \text { Transport Spatial Filter Vacuum System (vacuum) } \\ \text { WBS 1.3.3.6 } & \text { Pockels Cell Vacuum System (vacuum) } \\ \text { WBS 1.3.2 } & \text { Amplifiers (temperature, gas flow, particle count/size) } \\ \text { WBS 1.8.1.5 } & \text { Target Chamber Vacuum System (vacuum) } \\ \text { WBS 1.2.2 } & \text { Laser Bay HVAC (temperature) } \\ \text { WBS 1.2.2 } & \text { Switchyard HVAC (temperature) } \\ \text { WBS 1.2.2 } & \text { Target Bay HVAC (temperature) } \\ \text { WBS 1.4 } & \text { Final Optics Mounts (temperature) } \\ \text { WBS 1.4 } & \text { Polarizer Mounts (temperature, RH) } \\ \text { WBS 1.4 } & \text { Transport Turning Mirror Mounts (temperature) } \\ \text { WBS 1.4 } & \text { Cavity Mirror Mounts (temperature) } \\ \text { WBS 1.4 } & \text { Amplifier Columns (temperature) }\end{array}$

\subsubsection{Major Subsystems}

Consists of WBSs:

1.5.6.1 Television Distribution

1.5.6.2 Communications

1.5.6.3 Facility Environment Monitor 


\subsubsection{Functional Requirements}

The Television distribution system shall:

- supply DC power to all alignment TV sensors that require it

- supply sync signals to all TV cameras and other video sources

- provide routing capability to connect any input to any output

- provide TV monitoring in control consoles and at remote operator stations

- provide remote graphical operator control panels

- provide remote control of routing from computer via the LAN

- identify sources with ID indicator overlaid on monitored images

- support a small, self contained, security approved TV router/switcher for use with classified targets that can be disconnected from the main system when classified operation is required.

The Communications system shall:

- provide voice communication services between operator stations

- access building public address system for announcements

- provide radio services to allow easy access to laser- and target-areas

- provide live television surveillance of variable high-hazard laser, target, and viewing gallery areas

The Facility environmental monitor shall:

- measure and display facility environmental parameters affecting laser performance

(temperature, humidity, oxygen gas content)

- display facility environmental parameters affecting laser performance

(vacuum pressure, argon flow, nitrogen flow, particle count, HVAC data)

- archive environmental parameters in on-line database

- provide graphical trending displays and reports

- provide software development environment for specialized computer equipment

- provide machine interlocks using environmental sensor data

\subsubsection{Facility Environmental Monitor Measurement \& Logging Interval}

The facility environmental monitor shall make measurements at 1 minute intervals (for alarm purposes) and log the measurements at 15 minute intervals into a permanent record for machine diagnostic and trending purposes.

\subsubsection{Facility Environmental Monitor Measurement, Machine Interlocks}

The Facility Environmental Monitor shall provide machine interlocks to the Supervisory Control Software for preventing system shots under adverse environmental conditions.

\subsubsection{Facility Environmental Monitor, Relative Humidity Monitor}

The relative humidity in the area of the KDP assembly and a sample of turning mirrors shall be measured to $1 \%$ accuracy for each KDP assembly and for a representative sample of the turning mirrors. A control room alarm and machine interlocks shall be implemented to prevent a shot when the results of these measurements is out of tolerance.

\subsubsection{Facility Environmental Monitor, Temperature Monitor}

The temperature in the area of the KDP assembly and a sample of turning mirrors and selected components shall be measured to $0.1^{\circ} \mathrm{C}$ accuracy. A control room alarm shall be issued and machine interlocks shall be implemented to prevent a shot if it is not maintained at the $20^{\circ} \mathrm{C} \pm 0.3^{\circ} \mathrm{C}$. setpoint.(per SDR001).

\subsubsection{Facility Environmental Monitor, SF Vacuum Monitor, Roughing}

Spatial Filter Roughing Vacuum system will have a range of 0.01 to 800 torr. Pressure shall be monitored to within 5\% accuracy and logged. A control room alarm shall be issued and machine interlocks shall be implemented to prevent a shot when the results of these measurements is out tolerance. 


\subsubsection{Facility Environmental Monitor, SF Vacuum Monitor, Hi-Vac}

Spatial Filter High Vacuum system will have a range of $10^{e-3}$ to 800 torr. Pressure shall be monitored to within 5\% accuracy near the operating point and logged. A control room alarm shall be issued and machine interlocks shall be implemented to prevent a shot when the results of these measurements is out of tolerance.

\subsubsection{Facility Environmental Monitor, Pockels Cell Vacuum Monitor}

Pockels Vacuum system will have a range of 0.00005 to 800 torr. Pressure shall be measured to within 5\% accuracy near the operating point and logged. A control room alarm shall be issued and machine interlocks shall be implemented to prevent a shot when the results of these measurements is out of range.

\subsubsection{Facility Environmental Monitor, Amplifier Oxygen Monitor}

Amplifier Oxygen content shall be measured and monitored to within 5\% accuracy near the operating point. If the oxygen content exceeds the alarm setpoint, the system shall hold the shot. A control room alarm shall be issued and machine interlocks shall be implemented to prevent a shot when the results of these measurements is out of range.

\subsubsection{Video Distribution}

Ancillary System shall implement a video distribution system to route any video input to any monitor location. This requirement can be met via a cross point analog switch or by other techniques such as digital video on the local area network. Basic requirements are:

Motion Video Minimum Requirements:

1. 2 operators per control room console ( 4 monitors) each viewing up to 2 images

2. 10 frames per second at 480 by 512 pixels by 8 bits

3. 2 cameras per beam must be viewable from one operator location at one time

The TV distribution system shall have the capacity of 5 sensors per beam $(5 * 192=960)$ plus a small number of other TV/imaging sources.

Minimum number of monitor channels shall be 32 . 


\subsubsection{Video, Variable Classified}

\section{Target}

Bay Cameras

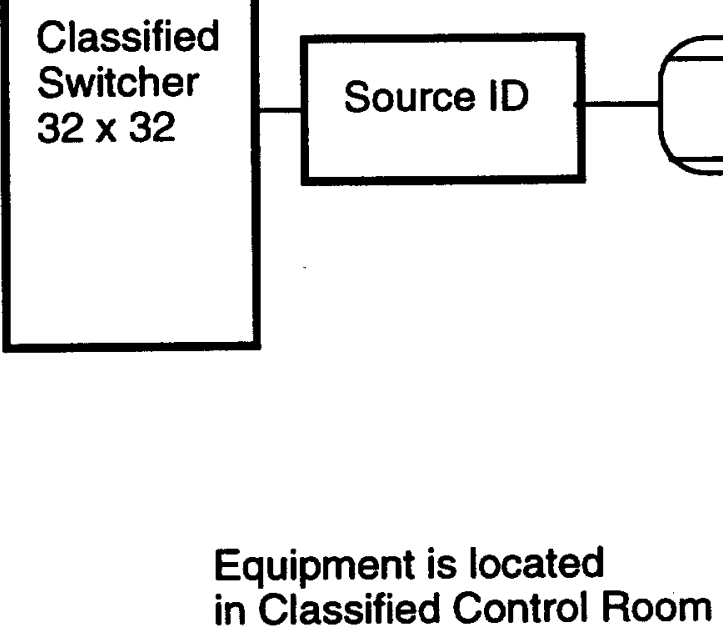
in Classified Control Room

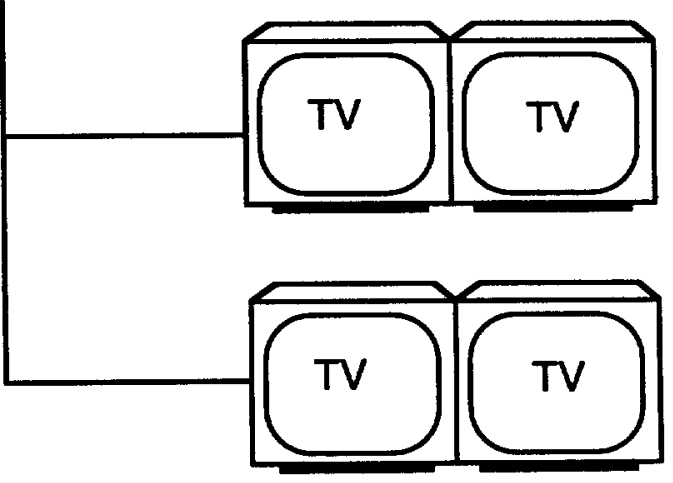

Classified Operator Console Monitors

Channel Proceed to Main Distribution System during Unclassified Operation Panel

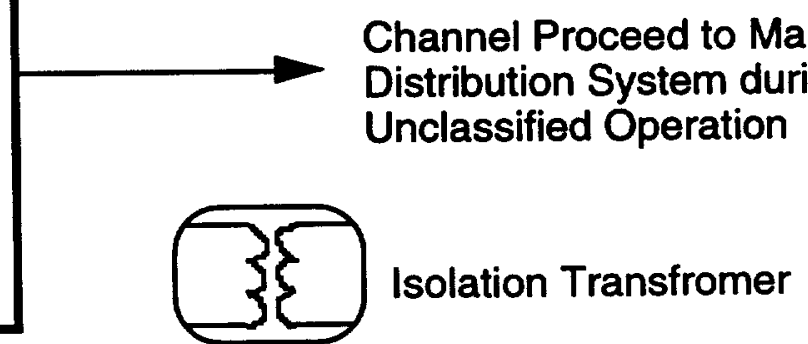

The video distribution system shall be capable of isolating a number of the inputs and outputs and place them on a separate distribution system for security purposes. The method used shall be acceptable to LLNL Security for the level of classification. This variable classified TV distribution system shall follow a LLNL approved Security Plan (to be supplied at a later date).

Target Bay camera sources include:

Target Area Sensor

Target Positioner

Backscatter
TR X-Ray Imaging Spectral X-Ray Shock Breakout
Neutron TOF

Neutron Imaging Soft X-ray
Static X-ray

Diagnostic Manipulators 


\subsubsection{Analog TV Video Interface}

The video signals on all analog TV equipment shall conform to EIA RS-170.

\subsubsection{TV Sensors Synchronization}

All TV sensors shall have the capability to gen-lock to an externally supplied source to allow synchronization of cameras to the pulsed laser source.

\subsubsection{TV Pulse Laser Operation}

All alignment and other pulsed laser TV sensors shall utilize the timing supplied by the Integrated Timing System to synchronize the TV frame with the pulsed laser.

\subsubsection{TV Surveillance System}

Ancillary Systems shall provide a separate TV surveillance system. It shall consist of 30 color TV cameras in strategic locations in the laser bays, target bay, capacitor bays, switch yards and viewing galleries to assist planning control room operations. Monitors in the operator consoles display the images.(WBS 1.5.1)

\subsubsection{Optical Communications Safety}

Where the Computer System uses lasers for optical communications, it shall conform to the applicable eye-hazard safety requirements to mitigate the possibility of eye exposure to an uncapped laser diode or unterminated active fiber source. Applicable standards include ANSI Z-136.1 (1993) and ANSI Z-136.2 (1988).

\subsubsection{Communications}

The Communication System shall provide the capability to patch in general announcements from control room consoles to the building public address system, WBS 1.2.2. The communication system shall remain operational for one hour during a power failure.

The Communication System shall provide intercoms between the operator consoles.

\subsubsection{FEP Software Requirement Specification}

The detailed requirements of each of the Ancillary Systems FEPs shall be documented in a separate Software Requirements Specification. The SRS shall include functional requirements for FEP-resident user interfaces, data processing, alarm processing, data logging, trending, device drivers, embedded controller interfacing, or other special hardware requirements.

The SRS shall also include performance or other dynamic requirements as well as other architectural requirements that may imply system partitioning. The FEP SRS shall describe functional requirements that are expected to be implemented by either the supervisory software or other collaborating FEPs.

All FEPs shall conform as much as possible to a common design for the implementation of functional requirements that are shared by more than one instance of an FEP.

\subsubsection{QA Level Requirement}

The Ancillary Systems shall adhere to the following Quality Level specifications. Reference for QA Level is the NIF QA Plan as stated in paragraph 2.6 of this document.

WBS 1.5.6.1 Television Distribution

WBS 1.5.6.2 Communications

WBS 1.5.6.3 Facility Environment Monitor
Q-Level 3

Q-Level 3

Q-Level 3 


\subsubsection{Lifetime, Replaceability, Reliability, Availability, Maintainability}

\subsubsection{Lifetime}

Lifetime: The Ancillary Systems shall operate for 30 years.

\subsubsection{Replaceability}

Any portion of the Ancillary Systems which cannot reasonably be designed for 30 year lifetime shall be designed to be replaced or repaired at reasonable cost in a timely manner consistent with the overall availability of the System.

\subsubsection{Reliability}

The Ancillary Systems shall have an overall reliability of $99.97 \%$. Reliability is defined as the probability of meeting the minimum requirements of the experiment per no-yield shot.

\subsubsection{Availability}

The Ancillary Systems shall have a shot availability of at least $99.81 \%$. The Ancillary Systems is unavailable when it is undergoing unplanned maintenance. Unplanned maintenance includes failure detection and active repair as well as logistic and administrative downtimes.

\subsubsection{Maintainability}

The Ancillary Systems shall have a scheduled maintenance plan that fits within an overall annual plant goal of 69 days. The unplanned maintenance goal is 0.5 days per year. Opportunistic maintenance activities are performed between shots and during other system downtimes.

\subsubsection{Recovery From an Abnormal Event}

The time required for the Ancillary Systems to recover from any abnormal event shall be less than the maximum times cited below, as a function of the expected yearly frequency of occurrence of the event.

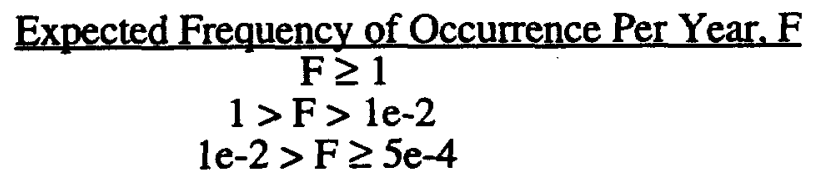

Maximum Recovery Time
24 hours
1 week
3 months

Probabilities listed in DOE-STD-1020-94 shall be used for natural phenomena.

For frequent events, the maximum allowed recovery time may be restricted by availability requirements to be less than that shown in the table above.

\subsubsection{Environmental/EMI Requirements}

\subsubsection{Environmental/EMI Requirements, Temperature and Humidity}

The Ancillary Systems shall be capable of operating in the temperature and humidity previously specified for the laser and target area building. In general, the Ancillary Systems components are capable of operating in a standard commercial temperature and humidity of $5^{\circ} \mathrm{C}$ to $40^{\circ} \mathrm{C}\left(41\right.$ to $\left.104^{\circ} \mathrm{F}\right)$ and $20 \%$ to $80 \% \mathrm{RH}$ non-condensing when installed in their appropriate enclosures.

\subsubsection{Environmental/EMI Requirements, Plenum Approved/CL2 Cabling}

All Ancillary Systems cabling installed in air plenums shall use plenum approved cabling. Otherwise controls cabling shall conform to CL2 specifications. 


\subsubsection{EMI Requirements}

All Ancillary Systems electronic equipment shall be designed or purchased to tolerate, where warranted, an operating environment of $50 \mathrm{~V} / \mathrm{m}$ external electrical field and $0.1 \mathrm{~A} / \mathrm{m}$ external magnetic field without adverse effects. (ref ANSI C95.1-1991)

Ionizing Radiation effects are an issue only inside the target room. Inside the target room careful consideration shall be given to the radiation and EMI effects as described in "Radiation and EMI Effects in the NIF Environment", UCRL-ID-118202.

\subsubsection{Ionizing Radiation}

Ionizing Radiation effects are an issue only inside the target room. Inside the target room careful consideration shall be given to the radiation and EMI effects as described in "Radiation and EMI Effects in the NIF Environment", UCRL-ID-118202.

\subsubsection{Segmented and Concurrent Operation}

The Ancillary Systems shall be capable of operating the NIF in a segmented mode with the segments functioning concurrently in different configurations. As an example, a portion of the laser may be under maintenance or construction and the rest of the laser operational. The Ancillary Systems shall support the area under construction with appropriate test sequences, diagnostics and construction debugging tools, while simultaneously supporting shot sequences on the operational segment of the laser.

\subsubsection{Human Factors}

The Ancillary Systems shall be designed in an ergonometric fashion to ensure that reliability during operation and maintenance is sustained at a level consistent with meeting overall availability and reliability objectives.

Consistency in displays, warnings, and human interfaces should be maintained throughout the Laser System and, if possible, throughout the NIF facility (i.e. GUI displays, access ports, tooling).

\subsubsection{Documentation and Records}

The Ancillary Systems shall provide sufficient documentation to comply with the NIF Quality Assurance Plan, and DOE Order 5700.6C, Quality Assurance, Criterion-4 Documents and Records, which states: "Documents shall be prepared, reviewed, approved, issued, used and revised to proscribe processes, specify requirements or establish design. Records shall be specified, prepared, reviewed approved and maintained."

Examples of documents that should be controlled include drawings, data files, calculations, specifications, computer codes, purchase orders, vendor supplied documents, procedures, work records and data sheets and test records. Revisions should be reviewed by the organizations that originally prepared and approved the documents. Controlled documents should be distributed to those doing the work.

\subsection{Logistics}

\subsubsection{Spares}

As a part of the design/construction project, the Ancillary Systems shall provide an initial complement of spare parts as required to activate the system.

\subsubsection{Maintenance}

As a part of the design/construction project, the Ancillary Systems shall provide all equipment required to inspect, service, and maintain all subsystems within the Ancillary Systems to meet the maintainability and availability requirements. Maintenance equipment shall include all handling fixtures, lifting equipment, and other special tools not otherwise available within the NIF, that are necessary to perform any planned (scheduled or unscheduled) maintenance activity. 
6.0 Revision Record

Rev Date Change by Description

letter

A 12Mar96 Severyn Convert to FileMaker, update

A 30May96 Severyn Post Mid Title-1 update

2 09Aug96 Severyn para 2.6, Change to new QA Plan reference (1995)

$2 \quad 20$ Aug96 Severyn

para 3.2.17, Update QA level to 1996 stds.

para 2.2 was TBD, added ref to DOE QA document

(flowdown), also changed Safeguards and Security to

"not applicable" (was TBD). para 2.3, General and

Safety sections were TBD, changed to "not applicable".

para 2.5 was TBD, added ref. to NIF Grounding Plan.

(flowdown from SDR4, signal isolation).

2 03Sep96 Clasen Convert to Word

2 03Sep96 Severyn Call rev B=rev 2 for Sherpa consistency.

$2 \quad$ 05Sep96 Severyn para 3.2.01.1, purged TBD per Reed.

para 3.2.01.2, purged TBD per Reed.

para 3.2.01.5, replaced "...if it is not maintained below a prescribed setpoint (TBD) within the above range." with, "when the results of this measurement are out of tolerance." per Reed.

para 3.2.01.6, replaced "...if it is not maintained below a prescribed setpoint (TBD) within the above range." with, "when the results of this measurement are out of tolerance." per Reed.

para 3.2.01.7, replaced "...if it is not maintained below a prescribed setpoint (TBD) within the above range." with, "when the results of this measurement are out of range." per Reed.

para 3.2.01.8, replaced "TBD\%" with "the alarm setpoint". per Reed.

para 3.2.01.8, replaced "...if it is not maintained below a prescribed setpoint (TBD) within the above range." with, "when the results of this measurement are out of range." per Reed. 


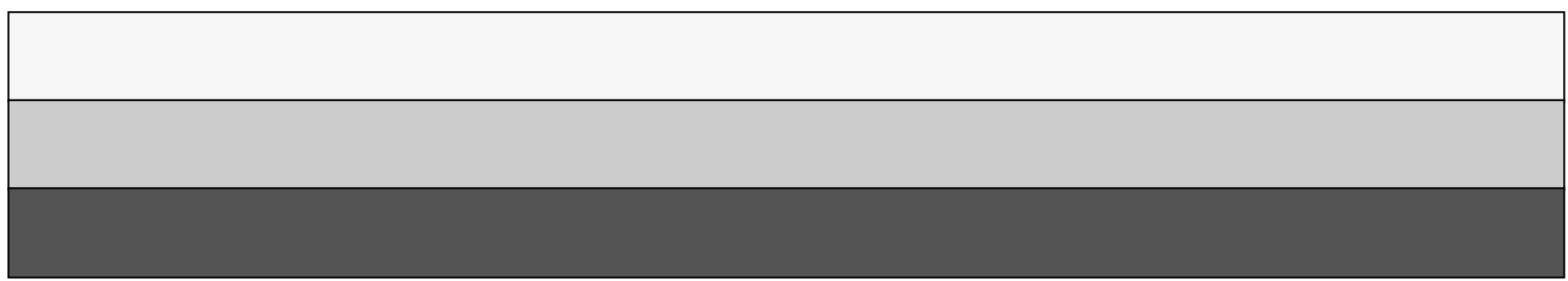

